\title{
Pengaruh Kualitas Pelayanan terhadap Loyalitas Pelanggan Mujigae Resto Depok
}

\author{
Yusthika Prasetya Probo Dewi ${ }^{1)}$, Iis Mariam²) dan Menik Wijiyanti' ${ }^{3)}$ \\ 1,2,3 Program Studi Administrasi Bisnis Terapan, Politeknik Negeri Jakarta \\ E-mail: 1yusthikaprasetya@gmail.com , 는. Iis.mariam@yahoo.com , ${ }^{3}$ menikwijiyanty@yahoo.com
}

\begin{abstract}
This research is conducted to analyze the influence of service quality toward costumer loyalty Mujigae Resto Depok. This is quantitative research with descriptive analysis. The sample of this research are people who ever come to Mujigae Resto Depok minimum two times in last six months. This research using validation test, reliability test, normality test, linearity test, and hypothesis test consisting of simple linear reggresion analysis, determination coefficient analysis (R2), partial statistic analysis ( $\mathrm{t}$ test), and simple linear reggresion analysis. Based on the result of determination coefficient analysis (R2), amount $34,9 \%$ of costumer loyalty Mujigae Resto Depok is influenced by service quality. It can be concluded that service quality has a significant influence toward costumer loyalty Mujigae Resto Depok.
\end{abstract}

Kata kunci: service quality, costumer loyalty, mujiage resto

\begin{abstract}
Abstrak
Penelitian ini bertujuan untuk menganalisis pengaruh kualitas pelayanan terhadap loyalitas pelanggan Mujigae Resto Depok. Penelitan ini adalah penelitian kuantitatif dengan menggunakan metode survei. Sampel penelitian yang digunakan adalah orang yang pernah makan dan berkunjung ke Mujigae Resto Depok minimal 2 kali dalam 6 bulan terakhir. Penelitian ini menggunakan uji metode validitas, uji reliabilitas, uji normalitas, uji linearitas, dan uji hipotesis yang terdiri dari analisis korelasi sederhana, analisis koefisiensi determinasi, analisis statistik parsial (uji t), dan uji regresi linier sederhana. Berdasarkan hasil koefisien determinasi (R2), sebesar 34,9\% loyalitas pelanggan Mujigae Resto Depok dipengaruhi oleh kualitas pelayanan. Sehingga dapat disimpulkan bahwa kualitas pelayanan memiliki pengaruh yang signifikan terhadap loyalitas pelanggan Mujigae Resto Depok.
\end{abstract}

Kata kunci: kualitas pelayanan, loyalitas pelanggan, mujigae resto

\section{PENDAHULUAN \\ Latar Belakang}

Di Indonesia, terdapat berbagai makanan atau kuliner dari berbagai penjuru dunia. Untuk itu, masyarakat tidak perlu jauh-jauh datang ke luar negeri untuk mencicipi makanan khas negara asal. Berdasarkan data statistik restoran/rumah makan 2015, tercatat 54,55 persen restoran/rumah makan menyajikan makanan khas Indonesia.
Untuk jenis masakan Amerika dan Eropa sebanyak 22,3 persen, dan masakan lainnya 12,33\%. (www.bps.go.id)

Beberapa tahun terakhir, perkembangan budaya Korea sudah menyebar ke seluruh Indonesia dalam bentuk film, drama, musik, kuliner serta pernak-pernik budaya Korea. Khususnya pada kuliner, para pengusaha memanfaatkan peluang ini untuk membuka bisnis restoran Korea. Hal ini 
ditandai dengan perkembangan restoran Korea di Indonesia yang semakin pesat. Di Jawa Barat, terjadi peningkatan jumlah restoran dari 2.687 restoran pada tahun 2015 menjadi 2.853 restoran pada tahun 2016. Depok merupakan kota urutan ke 2 dengan jumlah restoran terbanyak yaitu 275 restoran, selisih 97 restoran dengan kota Bandung yaitu 372 restoran.

Saat ini di Depok terdapat beberapa restoran Korea, salah satunya adalah Mujigae Resto yang terletak di Margo City Lt Ground (North Gate) Jl Margonda Raya, Depok, Kemiri Muka, Beji, Kota Depok, Jawa Barat 16436. Mujigae Resto ini merupakan salah satu restoran terbaik di Depok.

Mujigae, Bibimbap and casual Korean Food merupakan restoran makanan Korea asal Indonesia yang menawarkan bibimbap dan aneka kuliner khas Korea dalam kemasan dan suasana yang memadukan unsur tradisional dan modern dengan harga terjangkau dan citarasa makanan yang menyesuaikan dengan selera masyarakat Indonesia.

Mujigae dengan gagasan full-service restaurant tidak hanya menyediakan makanan dan minuman Korea casual yang berkualitas, namun juga aneka sarana hiburan dengan perangkat teknologi digital. Mujigae memposisikan sebagai restoran yang akan memberikan pelanggan pengalaman makan dengan value of money yang tinggi. Fasilitas yang disediakan oleh Mujigae Resto diimbangi dengan pelayan yang selalu siap memberikan pelayanan yang baik dan cepat kepada pelanggan serta membantu untuk memenuhi kebutuhan pelanggan yang merasa kesulitan dalam memilih pesanan yang diinginkan. Pelayanan yang baik harus selalu berorientasi kepada kebutuhan pelanggan sehingga tercipta kepuasan pelanggan yang membuat pelanggan akan menjadi loyal.

Berlandaskan perpaduan produk, pelayanan dan pengalaman makan yang berkualitas, Mujigae Resto berhasil mendapatkan penghargaan Top Brand
Award 2016 sebagai restoran Korea yang memiliki mind share, market share dan commitment share diantara konsumen. Mujigae menduduki peringkat 1 dengan Top Brand Index 28,1\%, menggungguli berbagai restoran Korea lain dengan selisih lebih dari 24 poin persentase. (www.serpongupdate.com)

Sebagai merek yang cukup baru, penghargaan tersebut merupakan suatu prestasi atas upaya untuk meraih kesuksesan. Namun tidak hanya itu, pada tahun 2017, Mujigae tetap menduduki peringkat 1 dengan Top Brand Index 27,3\% dengan selisih lebih dari 22 poin persentase dengan restoran lain. (www.topbrand-award.com). Selain itu, Mujigae Resto merupakan restoran Korea pertama yang mempunyai sertifikasi halal dari MUI. Hal ini diumumkan pada 10 Mei 2017 melalui media sosial instagram bahwa produknya halal karena telah mempunyai sertifikat halal resmi dari Majelis Ulama Indonesia (MUI) dengan nomor sertifikasi 17160029350117.

Berdasarkan latar belakang di atas, penulis tertarik mengadakan penelitian dan membahas kualitas pelayanan terhadap loyalitas pelanggan. Oleh karena itu, penulis mengangkat judul "Pengaruh Kualitas Pelayanan terhadap Loyalitas Pelanggan Mujigae Resto Depok”.

\section{Kajian Pustaka \\ Kualitas Pelayanan}

Kualitas Pelayanan menurut Lewis dan Booms dalam Tjiptono dan Chandra (2011:157) bisa diartikan sebagai ukuran seberapa bagus tingkat layanan yang diberikan mampu sesuai dengan ekspektasi pelanggan.

Dimensi kualitas pelayanan menurut Parasuraman dalam Hurriyati (2015:100) mengemukakan lima dimensi kualitas jasa, yaitu:

1. Keandalan (reliability), yaitu kemampuan untuk memberikan pelayanan yang dijanjikan dengan tepat (accurately) dan kemampuan untuk dipercaya (dependably), 
terutama memberikan jasa secara tepat waktu (on time), dengan cara yang sama sesuai dengan jadwal yang telah dijanjikan, dan tanpa melakukan kesalahan.

2. Daya tanggap (responsiveness), yaitu kemauan atau keinginan para karyawan untuk membantu memberikan jasa yang dibutukan konsumen.

3. Jaminan (assurance), meliputi pengetahuan, kemampuan, keramahan, kesopanan, dan sifat dapat dipercaya dari kontak personal untuk menghilangkan sifat keraguraguan konsumen dan membuat mereka merasa bebas dari bahaya dan risiko.

4. Empati (emphaty), yang meliputi sikap kontak personal atau perusahaan untuk memahami kebutuhan dan kesulitan konsumen, komunikasi yang baik, perhatian pribasi, dan kemudahan untuk melakukan komunikasi atau hubungan.

5. Produk-produk fisik (tangibles), tersedianya fasilitas fisik, perlengkapan dan sarana komunikasi, dan lain-lain yang bisa dan harus ada dalam proses jasa.

\section{Loyalitas Pelanggan}

Loyalitas pelanggan menurut Oliver dalam Kotler dan Keller (2009:138), yaitu Loyalitas (loyalty) sebagai komitmen yang dipegang secara mendalam untuk membeli atau mendukung kembali produk atau jasa yang disukai dimasa depan meski pengaruh situasi dan usaha pemasaran berpotensi menyebabkan pelanggan beralih.

Indikator penilaian loyalitas pelanggan menurut Kotler dan Keller (2009: 138) adalah kesetiaan terhadap pembelian produk (repeat purchase), memberikan referensi kepada orang lain (referral), menunjukan kekebalan terhadap tarikan dari pesaing atau tidak mudah terpengaruh oleh bujukan pesaing (retention)

\section{METODE PENELITIAN}

Metode penelitian yang digunakan dalam penelitian ini yaitu penelitian survei yang merupakan salah satu bagian dari pendekatan penelitian kuantitatif. Penelitian ini termasuk penelitian kuantitatif karena tujuan akhir dari penelitian ini adalah menguji dan menunjukan pengaruh antarvariabel menggunakan teknik analisis data statistik yaitu regresi linier sederhana.

Variabel yang digunakan dalam penelitian ini terdiri dari satu variabel independen (X) dan satu variabel dependen (Y). Variabel independen (X) dalam penelitian ini yaitu kualitas pelayanan, sedangkan variabel dependen (Y) dalam penelitian ini yaitu loyalitas pelanggan.

Hubungan antara variabel independen (X) dan variabel dependen (Y) dalam penelitian ini dapat dilihat pada gambar 3.1 di bawah ini, yaitu:

Kualitas Pelayanan (X) $\longrightarrow$ Loyalitas Pelanggan (Y)

Dalam penelitian ini populasi yang dimaksud adalah semua orang yang pernah berkunjung dan makan di Mujigae Resto Depok yang jumlahnya tidak diketahui. jumlah sampel yang akan diambil pada penelitian ini yaitu 96 orang namun dibulatkan menjadi 100 orang dengan menggunakan rumus Lemeshow. Teknik pengambilan sampel pada penelitian ini menggunakan non probability sampling dengan teknik sampling purposive. Kriteria sampel yang digunakan dalam penelitian ini yaitu responden yang akan dijadikan sampel, yaitu Pria/wanita, Berusia 15 tahun atau lebih dan Pernah berkunjung dan makan ke Mujigae Resto Depok minimal 2 kali dalam 6 bulan terakhir.

Data dalam penelitian ini diperoleh dari data primer dengan menggunakan kuesioner dan data sekunder yang diambil melalui internet, referensi buku dan literatur-literatur lainnya. 
Data diolah menggunakan bantuan software Statistical Package for Social Science (SPSS).

\section{Uji Validitas}

Validitas atau kesahihan menunjukan sejauh mana suatu alat ukur mampu mengukur apa yang ingin diukur. Untuk hipotesis asosiatif, bila data ke dua variabel berbentuk interval atau ratio, maka menggunakan teknik statistik korelasi product moment. Dengan menggunakan rumus korelasi product moment, jika $r$ hitung untuk $r$ tiap butir pertanyaan positif, serta $r$ hitung $>r$ tabel maka butir pertanyaan tersebut dikatakan valid . Namun, jika $r$ hitung $<r$ tabel maka butir pertanyaan tersebut dikatakan tidak valid.

\section{Uji Reliabilitas}

Reliabilitas bertujuan untuk mengetahui sejauh mana hasil pengukuran tetap konsisten, apabila dilakukan pengukuran dua kali atau lebih dengan menggunakan alat pengukur yang sama. (Siregar, 2014: 87)

Kriteria suatu instrumen penelitian dikatakan reliabel dengan menggunakan alpha cronbach, bila koefisien reliabilitas (r) $>0,6$.

\section{Uji Normalitas}

Uji normalitas terhadap serangkaian data adalah untuk mengetahui apakah populasi data berdistribusi normal atau tidak. "Data berdistribusi normal jika probabilitas (sig) $>$ taraf signifikansi $\alpha$, sedangkan data tidak berdistribusi normal jika probabilitas (sig) < taraf signifikansi a." (Siregar, 2014: 167)

\section{Uji Linearitas}

Uji linearitas dilakukan untuk mengetahui apakah antara variabel tak bebas dan variabel bebas mempunyai hubungan linear.

Uji ini biasanya digunakan sebagai prasyarat dalam penerapan metode regresi linear. Pengujian pada software SPSS menggunakan test for linerarity dengan taraf signifikansi $10 \%(0,10)$. Variabel independen $(\mathrm{X})$ dan variabel dependen (Y) memiliki hubungan yang liner jika signifikansi (linearity) < 0,10.

\section{Uji Regresi Linear Sederhana}

Analisis regreasi linear sederhana adalah hubungan secara linear antara satu variabel independen $(\mathrm{X})$ dengan variabel dependen (Y). Analisis ini digunakan untuk mengetahui arah hubungan antara variabel independen dengan variabel dependen apakah positif atau negatif."

Rumus regresi linear sederhana (Umar, 2010: 294-295), yaitu:

Keterangan:

$\mathrm{Y} \quad=$ variabel tidak bebas

$\mathrm{X} \quad=$ variabel bebas

$\alpha \quad=$ tidak intercept (konstan)

b = koefisien arah regresi

\section{Koefisiensi Korelasi Sederhana}

Koefisien korelasi digunakan untuk mengetahui derajat atau kekuatan dan arah hubungan antara dua variabel.

Menurut Sugiyono (2014:184), pedoman untuk memberikan interpretasi koefisien korelasi yaitu sebagai berikut:

$$
\begin{aligned}
& 0,00-0,199=\text { sangat rendah } \\
& 0,20-0,399=\text { rendah } \\
& 0,40-0,599=\text { sedang } \\
& 0,60-0,799=\text { kuat } \\
& 0,40-1,000=\text { sangat kuat }
\end{aligned}
$$

\section{Koefisiensi Determinasi}

Koefisien determinasi pada dasarnya digunakan untuk mengukur seberapa jauh kemampuan model regresi dalam menerangkan variabel-variabel dependen. Nilai koefisien determinasi adalah antara nol (0) dan satu (1). Nilai yang mendekati satu (1) berarti variabel-variabel independen memberikan hampir semua informasi yang dibutuhkan untuk memprediksi variabel dependen.

Koefisien determinasi dihitung dengan mengkuadratkan koefisien korelasi yang telah ditemukan dan selanjutnya dikalikan 
dengan 100\%. (Sugiyono, 2014:154). Koefisien determinasi dapat dirumuskan sebagai berikut:

$$
K D=R^{2} \times 100 \%
$$

\section{Uji T}

Untuk menguji signifikansi hubungan, yaitu apakah hubungan yang ditentukan itu berlaku untuk seluruh populasi. Kriteria pengujian adalah jika t hitung > tabel maka terdapat pengaruh yang signifikan antara variabel independen (X) dengan variabel dependen (Y). Sebaliknya, jika t hitung $<\mathrm{t}$ tabel maka tidak terdapat pengaruh yang signifikan antara variabel independen (X) dengan variabel dependen (Y).

\section{HASIL DAN PEMBAHASAN}

Hasil penelitian mengenai pengaruh kualitas pelayanan terhadap loyalitas pelanggan Mujigae Resto Depok melalui kuesioner akan disajikan dalam bentuk tabel yang berisi jumlah jawaban responden dan persentasenya terhadap pertanyaan-pertanyaan kuesioner.

Tabel 1. jumlah jawaban responden

\begin{tabular}{ll}
\hline Variabel & Indikator \\
\hline & $\begin{array}{l}\text { 1. Keandalan } \\
\text { (Reliability) }\end{array}$ \\
& $\begin{array}{l}\text { 2. Daya Tanggap } \\
\text { (Responsiveness) }\end{array}$ \\
Kualitas & 3. Jaminan (Assurance) \\
Pelayanan (X) & 4. Empati (Empathy) \\
& 5. Bukti Fisik \\
& (Tangibles) \\
& 1. Pembelian Ulang \\
& 2. Memberikan referensi \\
kepada orang lain \\
Pelanggan (Y) & 3. Kebal terhadap produk \\
& pesaing \\
\hline
\end{tabular}

Sumber: Data diolah, 2018

\section{Uji Validitas}

Dengan diketahui $\mathrm{df}=\mathrm{N}-2$, jumlah responden sebanyak 100 orang, dan taraf signifikansi 5\% $(0,05)$, berdasarkan tabel $r$ product moment, $r$ tabel yang diperoleh yaitu sebesar 0,1966, maka butir pertanyaan tersebut dinyatakan valid. Begitu pula sebaliknya, jika suatu butir pertanyaan memiliki $\mathrm{r}$ bilang $<\mathrm{r}$ tabel $=$ 0,1966, maka butir pertanyaan tersebut dinyatakan tidak valid.

Hasil uji validitas variabel kualitas pelayanan (X) dan loyalitas pelanggan (Y) pada penelitian lapangan yaitu semua butir pertanyaan pada variabel kualitas pelayanan (X) dan loyalitas pelanggan (Y) memiliki $r$ hitung yang lebih besar daripada nilai $r$ tabel. Dengan demikian dapat disimpulkan bahwa semua butir pertanyaan pada variabel loyalitas pelanggan (Y) tersebut dinyatakan valid.

\section{Uji Reliabilitas}

Uji reliabilitas pada penelitian ini dilakukan dua kali yaitu pada saat pre-test dan penelitian lapangan.

Hasil uji relibilitas variabel kepuasan pelanggan (X) dapat dilihat pada tabel 2 di bawah ini, yaitu:

Tabel 2. Hasil Uji Reliabilitas Variabel Kualitas Pelayanan (X)

\begin{tabular}{cc}
\multicolumn{2}{c}{ Reliability Statistics } \\
\hline Cronbach's Alpha & N of Items \\
\hline $\mathbf{0 , 8 0 9}$ & 22 \\
\hline
\end{tabular}

Sumber: Data Primer Diolah 2018

Pada tabel 2 di atas dapat dilihat bahwa variabel kualitas pelayanan (X) memiliki koefisiensi reliabilitas yaitu sebesar 0,809. Hal ini menunjukan bahwa variabel kualitas pelayanan (X) tersebut dinyatakan reliabel.

Hasil uji reabilitas variabel loyalitas pelanggan (Y) pada penelitian lapangan dapat dilihat pada tabel 3 di bawah ini, yaitu:

Tabel 3. Hasil Uji Reliabilitas Loyalitas Pelanggan (Y)

Reliability Statistics

\begin{tabular}{ll}
\hline Cronbach's Alpha & N of Items \\
\hline $\mathbf{0 , 8 9 1}$ & 21 \\
\hline
\end{tabular}

Tabel 3 menunjukan bahwa variabel loyalitas pelanggan (Y) memiliki koefisien reliabilitas yaitu sebesar 0,891. Hal ini menunjukan bahwa variabel loyalitas pelanggan $(\mathrm{Y})$ reliabel karena 
memiliki nilai koefisiensi reliabilitas di atas 0,6.

\section{Uji Normalitas}

Uji normalitas dapat dilakukan dengan menggunakan uji kolmogorov-smirnov. Pada uji kolmogorov-smirnov ini, data berdistribusi normal jika probabilitas (sig) $>$ taraf signifikansi $\alpha=5 \% \quad(0,05)$, sedangkan data tidak berdistribusi normal, jika nilai probabilitas probabilitas (sig) < taraf signifikansi $\quad \alpha=5 \%(0,05)$.

Hasil uji normalitas menggunakan uji kolmogorov-smirnov dapat dilihat pada tabel 4 di bawah ini, yaitu:

Tabel 4. Hasil Uji Normalitas

One-Sample Kolmogorov-Smirnov Test

\begin{tabular}{|c|c|c|}
\hline & & $\begin{array}{l}\text { Unstandardized } \\
\text { Residual }\end{array}$ \\
\hline \multicolumn{2}{|l|}{$\mathrm{N}$} & 100 \\
\hline \multirow{2}{*}{$\begin{array}{l}\text { Normal } \\
\text { Parameters }\end{array}$} & Mean & ,0000000 \\
\hline & $\begin{array}{l}\text { Std. } \\
\text { Deviation }\end{array}$ & 9,15960178 \\
\hline \multirow{3}{*}{$\begin{array}{l}\text { Most Extreme } \\
\text { Differences }\end{array}$} & Absolute & ,054 \\
\hline & Positive & ,038 \\
\hline & Negative &,- 054 \\
\hline \multicolumn{2}{|l|}{ Test Statistic } & ,054 \\
\hline \multicolumn{2}{|c|}{ Asymp. Sig. (2-tailed) } & 200 \\
\hline
\end{tabular}

Sumber: Data Primer Diolah 2018

Berdasarkan tabel 4 di atas dapat diketahui bahwa probabilitas (sig) yang diperoleh yaitu 0,200 Nilai probabilitas (sig) tersebut lebih besar dari taraf signifikansi penelitian yaitu 5\% $(0,05)$. Dengan demikian, dapat disimpulkan bahwa berdasarkan uji normalitas kolmogorov-smirnov data berdistribusi normal

\section{Uji Linearitas}

Uji ini digunakan sebagai prasyarat dalam penerapan metode regrasi linear. Variabel independen (X) dan variabel dependen ( $\mathrm{Y}$ ) memiliki hubungan yang linear jika signifikansi (linearity) $<$ taraf signifikansi $<5 \%(0,05)$.
Hasil uji linearitas pada penelitian ini dapat dilihat pada tabel 5 di bawah ini, yaitu:

Tabel 5. Hasil Uji Linearitas

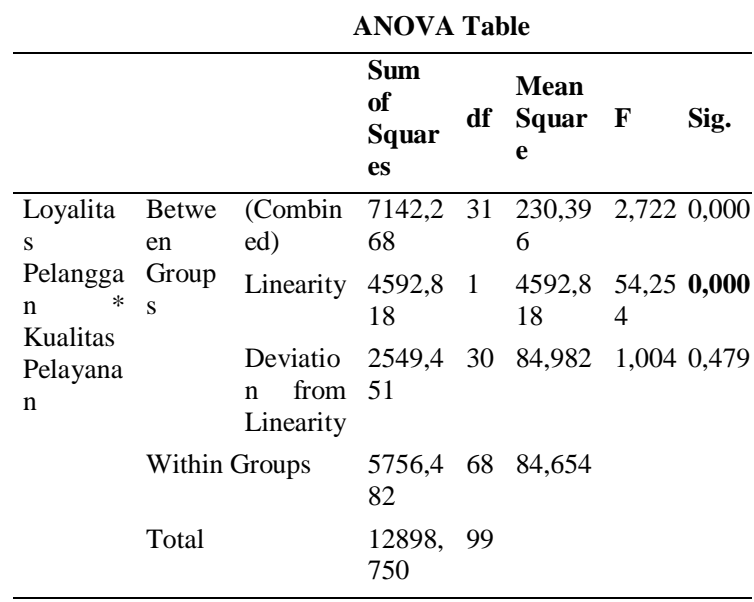

Sumber: Data Primer Diolah 2018

Berdasarkan tabel 5 di atas dapat diketahui bahwa signifikansi (linearity) yaitu sebesar 0,000. Nilai tersebut lebih kecil dari taraf signifikansi penelitian yaitu 5\% $(0,05)$. Dengan demikian, dapat disimpulkan bahwa antara variabel kualitas pelayanan (X) dan variabel loyalitas pelanggan (Y) memiliki hubungan yang linear.

\section{Analisis Regresi Linear Sederhana}

Analisis regresi linear sederhana digunakan untuk mengetahui arah hubungan antar variabel independen (X) dan variabel dependen (Y) apakah positif atau negatif.

Hasil analisis regresi linear sederhana pada penelitian ini dapat dilihat pada tabel 6 di bawah ini, yaitu:

Tabel 6. Analisis Regresi Linear Sederhana

Coefficients $^{\mathrm{a}}$

\begin{tabular}{|c|c|c|c|c|c|}
\hline \multirow{2}{*}{ Model } & $\begin{array}{l}\text { Unstan } \\
\text { Coeffic }\end{array}$ & $\begin{array}{l}\text { lardized } \\
\text { ents }\end{array}$ & $\begin{array}{l}\text { Standardized } \\
\text { Coefficients }\end{array}$ & \multirow{2}{*}{$\mathbf{t}$} & \multirow{2}{*}{ Sig. } \\
\hline & B & $\begin{array}{l}\text { Std. } \\
\text { Error }\end{array}$ & Beta & & \\
\hline 1 (Constant) & $-6,362$ & 10,556 & &,- 603 & ,548 \\
\hline $\begin{array}{l}\text { Kualitas } \\
\text { Pelayanan }\end{array}$ & ,917 & ,125 & ,597 & 7,361 & ,000 \\
\hline
\end{tabular}

Berdasarkan tabel 6 di atas maka persamaan regresi yang diperoleh pada penelitian ini, yaitu: 


$$
\mathrm{Y}=-6,363+0,917 \mathrm{X}
$$

Penjelasan persamaan regresi di atas yaitu konstanta yang diperoleh pada penelitian ini sebesar -6,363 artinya loyalitas pelanggan (Y) akan turun ketika variabel kualitas pelayanan tetap. Nilai koefisien arah regresi pada penelitian ini yaitu positif 0,917, artinya jika ada penambahan satu nilai atau angka pada kualitas pelayanan (X) maka akan ada kenaikan pada variabel loyalitas pelanggan (Y) sebesar 0,917.

\section{Koefisien Korelasi Sederhana}

Koefisien Korelasi digunakan untuk mengetahui derajat keeratan hubungan antara variabel independen $(\mathrm{X})$ dengan variabel dependen $(\mathrm{Y})$. Untuk data yang berbentuk interval, teknik korelasi yang digunakan adalah korelasi product moment.

Hasil koefisien korelasi sederhana pada penelitian ini dapat dilihat pada tabel 7 di bawah ini, yaitu:

Tabel 7. Hasil Koefisien Korelasi Sederhana

\begin{tabular}{llrr}
\multicolumn{4}{c}{ Correlations } \\
\hline & \multicolumn{1}{c}{$\begin{array}{l}\text { Kualitas } \\
\text { Pelayanan }\end{array}$} & $\begin{array}{l}\text { Loyalitas } \\
\text { Pelanggan }\end{array}$ \\
\hline Kualitas & Pearson Correlation & 1 &, $597^{* *}$ \\
Pelayanan & Sig. (2-tailed) & 100 &, 000 \\
& N &, $597^{* *}$ & 100 \\
Loyalitas & Pearson Correlation &, 000 & 1 \\
Pelanggan & Sig. (2-tailed) & 100 & 100 \\
& N & & \\
\hline **. Correlation is significant at the 0.01 level (2-tailed). & \\
Sumber: Data Primer Diolah 2018 &
\end{tabular}

Berdasarkan tabel 7 di atas maka koefisien korelasi sederhana antara variabel kualitas pelayanan (X) dan loyalitas pelanggan (Y) sebesar 0,597. Berdasarkan pedoman interprestasi korelasi yang telah dikemukakan oleh Sugiyono di atas, dapat disimpulkan bahwa terjadi hubungan yang sedang antara variabel kualitas pelayanan (X) dan loyalitas pelanggan (Y).

\section{Koefisien Determinasi}

Koefisien determinasi pada dasarnya digunakan untuk mengukur seberapa jauh kemampuan model regresi dalam menerangkan variabel-variabel dependen. Nilai koefisien determinasi adalah antara nol (0) dan satu (1). Nilai yang mendekati satu (1) berarti variabel-variabel independen memberikan hampir semua informasi yang dibutuhkan untuk memprediksi variabel dependen.

Hasil koefisien determinasi pada penelitian ini dapat dilihat pada Tabel 8 di bawah ini, yaitu:

Tabel 8. Hasil Koefisien Determinasi

\begin{tabular}{lllll}
\multicolumn{5}{c}{ Model Summary } \\
\hline Model & $\mathbf{R}$ & $\begin{array}{l}\text { R } \\
\text { Square }\end{array}$ & $\begin{array}{l}\text { Adjusted } \\
\text { R Square }\end{array}$ & $\begin{array}{l}\text { Std. Error of } \\
\text { the Estimate }\end{array}$ \\
\hline 1 &, $597^{\mathrm{a}}$ & $\mathbf{3 5 6}$ &, 349 & 9,20622 \\
\hline
\end{tabular}

a. Predictors: (Constant), Kualitas Pelayanan

Sumber: Data Primer Diolah 2018

Pada tabel 8 di atas diperoleh koefisien determinasi sebesar 34,9\%. Angka ini diperoleh dengan cara mengkuadratkan koefisien korelasi $(R$ Square $)=0,356$ yang telah ditemukan, dan selanjutnya dikalikan dengan 100\%. Berdasarkan hal tersebut, maka dapat disimpulkan variabel kualitas pelayanan (X) memiliki pengaruh terhadap variabel loyalitas pelanggan (Y) sebesar 34,9\%, sedangkan sisanya yaitu sebesar $65,1 \%$ dipengaruhi oleh faktor lain yang tidak diteliti. Adapun faktor lain yang tidak diteliti memberikan pengaruh yang lebih besar dalam menciptakan loyalitas dibandingkan faktor kualitas pelayanan. Menurut Gupta, Mc Laughin dan Gomez (2007) bahwa terdapat tiga faktor yang dapat meningkatkan loyalitas, yaitu selain kualitas pelayanan, faktor lainnya yaitu kualitas makanan dan harga.

\section{Uji T}

Uji signifikansi digunakan untuk menguji signifikansi hubungan, yaitu apakah hubungan yang ditentukan itu berlaku untuk seluruh populasi. Untuk pengujian signifikansi ini digunakan statistik t.

Hasil uji signifikansi pada penelitian ini dapat dilihat pada tabel 9 di bawah ini, yaitu: 
Tabel 9. Hasil Uji T

\begin{tabular}{|c|c|c|c|c|c|}
\hline \multicolumn{6}{|c|}{ Coefficients $^{\mathrm{a}}$} \\
\hline \multirow{2}{*}{ Model } & $\begin{array}{l}\text { Unstan } \\
\text { Coeffic }\end{array}$ & $\begin{array}{l}\text { dardized } \\
\text { ients }\end{array}$ & $\begin{array}{l}\text { Standardized } \\
\text { Coefficients }\end{array}$ & \multirow{2}{*}{$\mathbf{t}$} & \multirow{2}{*}{ Sig. } \\
\hline & B & $\begin{array}{l}\text { Std. } \\
\text { Error }\end{array}$ & Beta & & \\
\hline \multirow{2}{*}{ 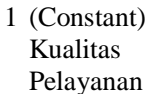 } & $-6,362$ & 10,556 & &,- 603 & ,548 \\
\hline & 917 & ,125 & ,597 & 7,361 & ,000 \\
\hline
\end{tabular}

Berdasarkan tabel 9 di atas diperoleh nilai t hitung sebesar 7,361. Nilai tersebut lebih besar dibandingkan dengan t tabel yaitu sebesar 1,660. Dengan demikian, dapat disimpulkan bahwa variabel kualitas pelayanan (X) berpengaruh signifikan terhadap variabel loyalitas pelanggan (Y).

\section{KESIMPULAN DAN SARAN}

Hasil yang diperoleh pada penelitian ini yaitu terdapat pengaruh yang signifikan antara kualitas pelayanan terhadap loyalitas pelanggan Mujigae Resto Depok. Hal ini dapat dilihat dari hasil penelitian ini, yaitu:

a. Berdasarkan analisis regresi linear sederhana, diketahui bahwa arah regresi pada penelitian ini yaitu positif dengan persamaan regresi $\mathrm{Y}=$ $-6,362+0,917 \mathrm{X}$, yang menunjukan bahwa apabila kualitas pelayanan Mujigae Resto Depok ditingkatkan satu nilai, maka akan meningkatkan loyalitas pelanggan sebesar 0,917.

b. Berdasarkan uji $\mathrm{T}$, diperoleh nilai $\mathrm{t}$ hitung sebesar 7,361 yang lebih besar dari $\mathrm{t}$ tabel yaitu 1,660. Hal ini menunjukkan bahwa kualitas pelayanan Mujigae Resto Depok berpengaruh signifikan terhadap loyalitas pelanggan Mujigae Resto Depok.

c. Berdasarkan nilai koefisien korelasi sebesar 0,597, terdapat hubungan yang sedang antara kualitas pelayanan Mujigae Resto Depok dan loyalitas pelanggan Mujigae Resto Depok.

Berdasarkan nilai koefisien determinasi, kualitas pelayanan Mujigae
Resto Depok memiliki pengaruh terhadap variabel loyalitas pelanggan Mujigae Resto Depok sebesar 34,9\%, sedangkan sisanya yaitu sebesar $65,1 \%$ dipengaruhi oleh faktor lain yang tidak diteliti yaitu kualitas makanan dan harga.

\section{DAFTAR PUSTAKA}

Buku:

Gaffar, Vanessa. 2007. CRM dan MPR Hotel. Alfabeta: Bandung.

Griffin, Jill. 2002. Costumer Loyalty. Erlangga: Jakarta.

Hurriyati, Ratih. 2015. Bauran Pemasaran dan Loyalitas Konsumen. Bandung: ALFABETA.

Indrawan, Rully dan R. Poppy Yaniawati. 2014. Metodologi Penelitian. Bandung: PT Refika Aditama

Kotler, Phillip dan Keller L. 2009. Manajemen Pemasaran, Edisi Ketiga Belas Jilid 2. Jakarta: PT Gelora Aksara Pratama.

Lovelock, Christopher H. dan Lauren K. Wright. 2007. Manajemen Pemasaran Jasa. Jakarta: Indeks.

Sangadji, Etta Mamang dan Sopiah. 2013. Perilaku Konsumen, Pendekatan Praktis Disertai Himpunan Jurnal Penelitian. Yogyakarta: Andi Offset.

Siregar, Syofian. 2014. Statistik Parametrik untuk Penelitian Kuantitatif. Jakarta: Bumi Aksara.

Sugiyono. 2011. Metodologi Penelitian Kuantitatif Kualitatif dan R\&D. Bandung: Alfabeta.

Tjiptono, F., Wahyudi, Basuki, S. dan Indro. 2007. Pemasaran Jasa. Cetakan keenam. Malang: Bayumedia.

Tjiptono, Fandy dan Gregorius Chandra. 2011. Service Quality \& Satisfaction. Edisi Ketiga. Yogyakarta: Andi.

Jurnal:

Gupta, S, Edward McLaughlin, Miguel Gomez. 2007. "Guest Satisfaction and Restaurant Performance.” Dalam EJournal Cornell University Volume 48, Issue 3, 284-289. 
Sumber Digital:

Majalah Serpong Update. 2016. Mujigae Raih Penghargaan Top Brand 2016. http://serpongupdate.com/mujigaeraih-penghargaan-top-brand-2016/ diakses 10 November 2017.

Top Brand Award. Top Brand Index 2017 Fase 2. http://www.topbrandaward.com/top-brand-survey/surveyresult/top_brand_index_2017_fase_2 diakses 10 November 2017

Sumber lain:

Badan Pusat Statistik Jawa Barat. 2017. Provinsi Jawa Barat dalam Angka 2017. BPS Jawa Barat. Jawa Barat

Kementerian Pariwisata dan Ekonomi Kreatif. 2014. Peraturan Menteri Pariwisata dan Ekonomi Kreatif Republik Indonesia Nomor 11 Tahun 2014 tentang Standar Usaha Restoran. Kementerian Pariwisata dan Ekonomi Kreatif Republik Indonesia. Jakarta. 
